\title{
SLAM EXCITATION SCALES FOR A LARGE WAVE PIERCING CATAMARAN AND THE EFFECT ON STRUCTURAL RESPONSE
}

Jason J. McVicar ${ }^{1}$ (V), Jason Lavroff ${ }^{1}(\mathrm{~V})$, Michael R. Davis ${ }^{1}$ (V) and Giles A. Thomas ${ }^{2}$ (V)

1. University of Tasmania, School of Engineering and ICT, Australia

2. University College London, Department of Mechanical Engineering, UK

\section{KEY WORDS}

Wave-Piercing; Catamaran; Slamming; Structural Response; Whipping

\section{INTRODUCTION}

A unique slamming process is observed on high speed wave piercing catamarans (WPCs) such as those manufactured by INCAT Tasmania (shown in Fig. 1). For conventional catamarans, wet-deck slamming constitutes a significant design load and is managed through proper design of the tunnel height for the proposed operating conditions. While methods have been developed for prediction of wet-deck slam occurrence and slam magnitude in conventional catamarans (for example Ge et al., 2005) the significant differences in geometry limit application to wave piercing catamarans. Although slamming of wave piercing catamarans may be categorised as a wet-deck slam, the INCAT Tasmania wave piercing catamarans include a forward centre bow to prevent deck diving which significantly alters the water entry and slamming characteristics.

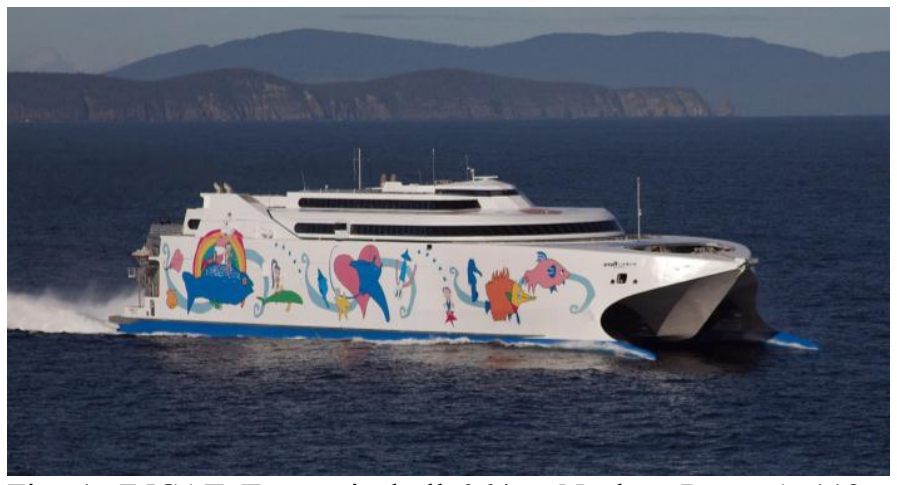

Fig. 1. INCAT Tasmania hull 064 - Nachan Rera. A 112m wave piercing catamaran.

Model scale experimental work by Shahraki (2014) Lavroff et al. (2011); and Amin (2009) and two dimensional drop tests by Whelan (2007) have shown that the most severe slams consist of three stages: a bottom slam on the demihulls, followed by entry of the centre bow and finally an arch slam. Fig. 2 shows the pressure distribution and free surface during centre bow entry. As a result, energy is imparted to the structure on multiple time scales with varying spatial distributions. For wave piercing catamarans, the slam force generates a significant longitudinal bending moment which can be the limiting design bending moment for such vessels (Lavroff et al., 2010 and Thomas et. al., 2003). It is therefore necessary to properly characterise the slam loads and the transmission of slam loads to the hull girder.
In addition to the difference in slam process compared to conventional craft, the ratio between the temporal hydrodynamic and structural scales differ (McVicar et al. 2015). While the demihulls of a wave piercing catamarans are relatively slender, the overall structure is not resulting in comparatively high two node bending frequencies. As a result of the combined complications arising from the unique slam process, the effects of the varying spatial and temporal excitation scales on the transmission of slam excitation to structural loads is not immediately clear. Moreover, to include global hydroelastic effects, it is necessary to first understand both the loads and their transmission to allow proper, simplified modelling of the coupled structural and hydrodynamic system.

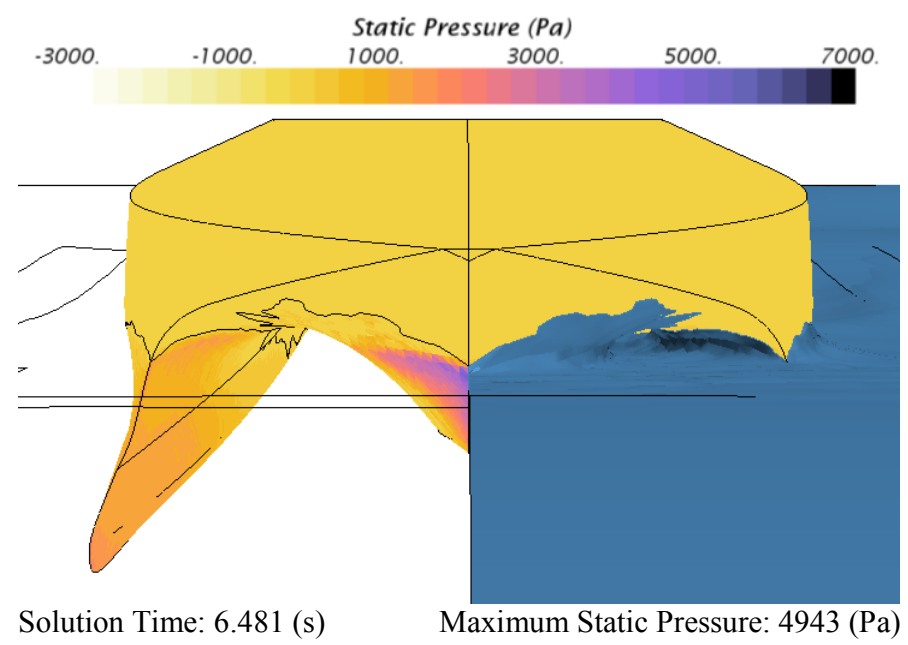

Fig. 2. CFD simulated pressure distribution (left) and free surface (right) acting on a $2.5 \mathrm{~m}$ model of a $112 \mathrm{~m}$ INCAT Tasmania catamaran (Lavroff, 2009) during centre bow entry prior to arch slam at $2.89 \mathrm{~m} / \mathrm{s}$ forward speed, $90 \mathrm{~mm}$ wave height and dimensionless encounter frequency of $\omega_{e}^{*}=4.869$.

A variety of methods exist for the estimation of slam loads including: potential flow solutions (Tuitman and Malenica, 2009), Computational Fluid Dynamics (CFD) (Varyani et al., 2001) and physical testing (Hermunstad et al., 1995). Accurate estimation of slam loads first requires precise prediction of vessel motions, as slamming loads are sensitive to the relative impact velocity. Prediction of slamming loads on INCAT Tasmania catamarans which include three dimensional effects has been predominantly conducted through model scale testing. Entry of the demihull and centre bow form jets which flow toward the top of the arch. Whelan (2007) obtained reasonable estimates of the slam forces acting on a two dimensional drop test model section using added mass theory. 
However, the two dimensional constraint gave rise to very high peak slam loads. Confluence of these jets and eventual closure of the arch precludes the use of potential flow solutions and the accuracy of simplified models for each of the separate slam event stages are limited in accuracy due to the interaction between the displaced jet flow formed.

In this paper, the discretised transient Reynolds Averaged Navier Stokes Equations (RANSE) are used to estimate the magnitude and scales of the spatial and temporal slam excitation. The transmission of these slam loads to the hull girder is then investigated through a simplified one way fluidstructure interaction and by analysing the effects of the spatial distribution of the slam excitation on the structural response in the context of a wave piercing catamaran. A parametric study of the structural vessel response is undertaken and it is shown that, in the case of wave piercing catamarans, the varying temporal and spatial scales of the various slam components result in significantly different contributions to the structural bending response. It is also shown that even modest variations to the slam location and duration can have a significant influence on the global bending loads.

\section{NUMERICAL SIMULATION}

Simulation was conducted at model scale $(1: 44.8)$ to allow direct comparison to the model scale tests conducted by Lavroff et al. (2013) who tested a hydroelastic segmented model in regular head seas. While oblique seas would impart additional asymmetric loads to the hull, head seas are generally considered the most severe slam condition. The model scale condition considered was a forward speed of $2.89 \mathrm{~m} \mathrm{~s}^{-1}$ with a wave height of $90 \mathrm{~mm}$, equivalent to 30 knots and $4 \mathrm{~m}$ wave height for a $112 \mathrm{~m}$ vessel. A dimensionless encounter frequency of $\omega_{e}^{*}=4.869$ was chosen which resulted in peak slam loading in model scale tests. The dimensionless encounter frequency is defined as:

$\omega_{e}^{*}=\omega_{e} \sqrt{\frac{L_{p p}}{g}}$ where $\omega_{e}$ is the encounter frequency in $\mathrm{rad} / \mathrm{s}$, and $g$ is the acceleration due to gravity. The selected encounter frequency gives a wavelength to ship length ratio of: $\lambda / L_{p p}=1.34$, where $\lambda$ is the wavelength and $L_{p p}$ is the vessel length between perpendiculars.

Numerical simulation was conducted using the commercially available RASNE based software package STAR-CCM+ using the finite volume method. Rigid body motion of the hull was implemented using an overset mesh and hydroelastic effects were not considered. A symmetry plane was used to reduce the computational domain. The upstream velocity inlet boundary is $1 L_{p p}$ (length between perpendiculars) forward of the bow; the downstream pressure outlet boundary was $2.4 L_{p p}$ aft of the stern; and the far port velocity inlet boundary was $1.4 L_{p p}$ from the port side. The domain extended $0.6 L_{p p}$ below the mean free surface (to represent the towing tank depth) and the same above the mean free surface. Both the upper and lower boundaries were velocity inlets. The water and air phases were modelled using an Eulerian volume of fluid approach and both phases were modelled as incompressible fluids. Turbulence modelling was achieved using the Shear Stress Transport (SST) $k-\omega$ turbulence model. In order to minimise reflections from the downstream pressure outlet, wave damping and coarsening of the mesh was applied in the region upstream of the outlet.

The mesh size, time step size and iterations per time step were investigated over a total of seven different simulations as summarised in Table 1. The solution was found to be particularly sensitive to time step size. The smallest time step size resulted in the largest estimated average peak slam force. The simulation is most sensitive to the time step, with the peak slam force increasing with each time step refinement. Due to prohibitively long simulation times, smaller time steps have not yet been tested. The smallest time step tested represents 5200 time steps per wave encounter and is necessary due to the significantly smaller time scale of the arch wet-deck slam relative to the wave encounter period.

Table 1. Summary of the model scale numerical simulation parameters and estimated motion and slam load

\begin{tabular}{|c|c|c|c|c|c|c|c|}
\hline & $\begin{array}{l}\text { Cell } \\
\text { count }\end{array}$ & Time step [s] & $\begin{array}{l}\text { Iterations per } \\
\text { time step }\end{array}$ & $\begin{array}{l}\text { Heave amplitude } \\
{[\mathrm{m}]}\end{array}$ & $\begin{array}{l}\text { Pitch amplitude } \\
\text { [rad] }\end{array}$ & $\begin{array}{c}\text { Mean Peak } \\
\text { Slam Force }[N]\end{array}$ & $\begin{array}{l}\text { Solver } \\
\text { time** }\end{array}$ \\
\hline \multirow{5}{*}{ Grid 0} & \multirow{5}{*}{$436 \mathrm{k}$} & \multirow{3}{*}{0.0005} & 5 & 0.02881 & 0.05467 & 180 & 2 \\
\hline & & & 10 & 0.02919 & 0.05592 & 191 & 4 \\
\hline & & & $20 *$ & 0.02907 & 0.0559 & 192 & 6 \\
\hline & & 0.00025 & 10 & 0.02899 & 0.05627 & 199 & 11 \\
\hline & & 0.000125 & 10 & 0.02909 & 0.05559 & 212 & 20 \\
\hline Grid 1 & $770 \mathrm{k}$ & 0.000375 & 5 & 0.02755 & 0.05511 & 194 & 5 \\
\hline Grid 2 & $1.4 \mathrm{M}$ & 0.00025 & 5 & 0.02772 & 0.05233 & 180 & 19 \\
\hline
\end{tabular}

* Rigid body motion solver restricted to 10 iterations per time step

** Solver time in days per wave encounter per cpu 
The experimental and simulated transient heave and pitch motions are presented in Fig. 3 and the force acting on the centre bow segment of the hydroelastic segmented model is plotted in Fig. 4. In all three cases, the simulation underpredicts the response. The encounter frequency of interest lies in a region with steep slope on the heave and pitch motion response amplitude operators as presented by Lavroff (2013) which is a region of high sensitivity to changes in conditions. In general the simulated transient force follows the same trend as the experimental data.
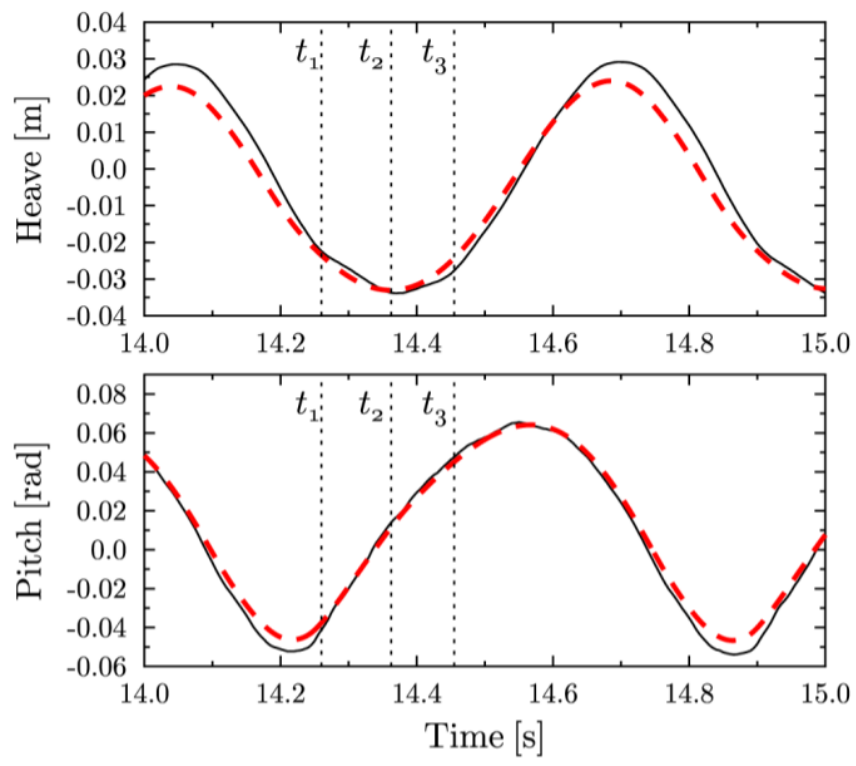

— Experiment - - Rigid body simulation

Fig. 3. Experimental and simulated model scale heave and pitch response for a forward speed of $2.89 \mathrm{~m} / \mathrm{s}$ and a wave height of $90 \mathrm{~mm}$ at a dimensionless encounter frequency of $\omega_{e}^{*}=4.869$.

Small amplitude high frequency oscillation is observable in the experimental heave response between $14.2 \mathrm{~s}$ and $14.5 \mathrm{~s}$ causing deviations in the otherwise smooth heave response at times $t_{1}$, $t_{2}$ and $t_{3}$ marked in Fig. 3 by the vertical dotted lines. Lavroff (2013) demonstrated that the whipping vibration following the slam results in oscillation of the transient centre bow force.
The periods of oscillation identified in the heave record $\left(t_{2}-t_{1}\right.$ and $\left.t_{3}-t_{2}\right)$ closely coincide with the periods of oscillation in the transient force record (see Fig. 4) demonstrating that the motion records are affected by structural flexibility. The first period of vibration is longer than the second due to temporal variation in added mass. As the simulation considered the model as rigid, these aspects of the motion cannot be captured in the simulation. Amin (2009) performed a direct comparison of the bow accelerations on a hydroelastic model of an INCAT Tasmania wave piercing catamaran fitted with flexible and rigid links and found no significant difference. Therefore, it is expected that there is minimal simulation error in peak forces due to neglecting the structural flexibility.

Slam loads, being sensitive to the relative velocities between the water free surface and the hull, require that motions be well predicted in order to accurately predict slam loads. It is therefore likely that the under-prediction of vessel motions lead to the under-prediction of slamming forces. Water entry of the demihulls occurs at $14.1 \mathrm{~s}$ and again at $14.75 \mathrm{~s}$ : this is evident in both simulated and experimental data records as a small negative dip in the centre bow force. Water entry of the centre bow commences at 14.16 s where the force acting on the centre bow steadily rises toward $90 \mathrm{~N}$ and $95 \mathrm{~N}$ for the first and second slams respectively in the record. The peak magnitude prior to the arch slam is predicted well by the simulation, however, the simulation over predicts the force during the initial bow entry stage. At $14.23 \mathrm{~s}$, and again at $14.88 \mathrm{~s}$, the archway formed by the centre bow and demihulls fills resulting in a short duration spike which is under-predicted by the simulation by $9 \%$ on average across all simulations. The mean, maximum and standard deviations of the experimental and simulated centre bow forces are presented in Table 2. It is possible that the under prediction of the force during wet-deck arch slamming is related to the over prediction of the initial centre bow entry force. As the centre bow entry occurs on a significantly longer time scale, relatively small increases in the entry force can alter the momentum balance causing the hull relative bow velocity at time of wet-deck arch slam to be reduced. However, this cannot be substantiated with the current data.

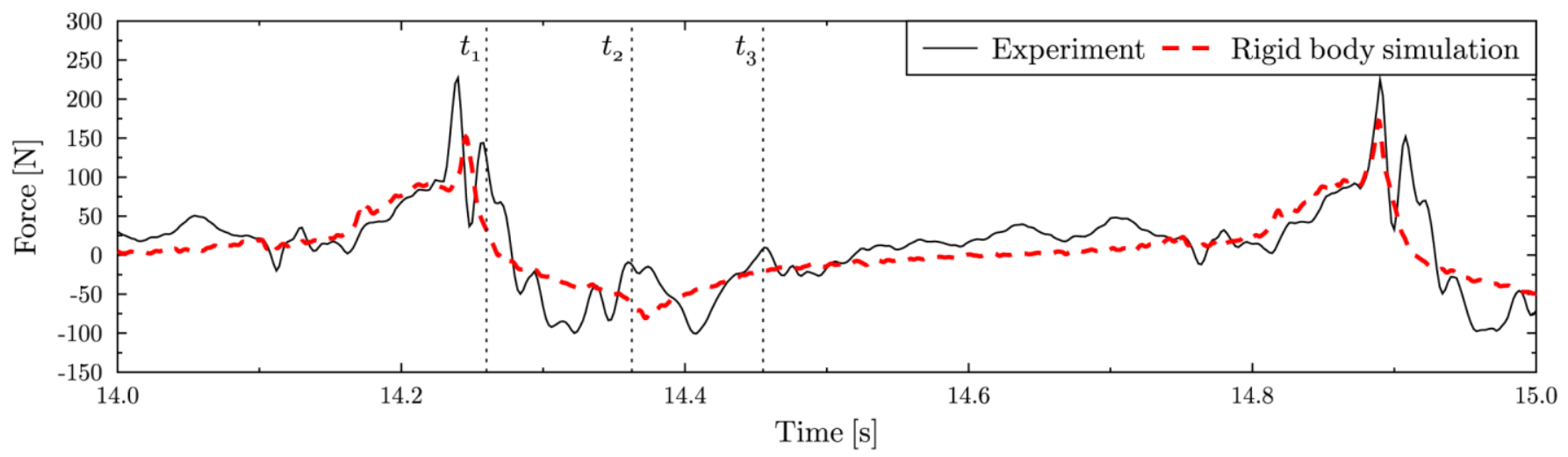

Fig. 4. Experimental and simulated model scale centre bow force for a forward speed of $2.89 \mathrm{~m} / \mathrm{s}$ and wave height of $90 \mathrm{~mm}$ at a dimensionless encounter frequency of $\omega_{e}^{*}=4.869$. 
Table 2. Mean, maximum and standard deviation of the peak force acting on the model centre bow segment.

\begin{tabular}{|l|l|l|}
\hline & Experimental & Simulation \\
\hline Mean & $212 \mathrm{~N}$ & $193 \mathrm{~N}$ \\
\hline Maximum & $227 \mathrm{~N}$ & $270 \mathrm{~N}$ \\
\hline Standard deviation & $9.5 \mathrm{~N}$ & $25.8 \mathrm{~N}$ \\
\hline
\end{tabular}

The pressure distribution predicted throughout a slam event using the RANSE method is shown in Fig. 5. As observed in the model scale tests, the forward ends of the demihulls are dry prior to the slam, and the overall slam event commences with a bottom slam on the demihulls with a characteristic distribution shown at a simulation time of $14.11 \mathrm{~s}$. In the condition tested, the bottom slam occurred over the forward third of the demihulls. Spatially, the demihull slam is distributed across 25 hull frames. At full scale, the frames are spaced at $1.2 \mathrm{~m}$ intervals, equivalent to $26.8 \mathrm{~mm}$ intervals at model scale. At the start of centre bow entry the smaller deadrise angle on the lower faces of the centre bow results in a high peak pressure, shown at a simulation time of $14.175 \mathrm{~s}$. As the centre bow enters further, the pressure distribution is similar to that seen in three-dimensional wedge entry with peak pressure at the leading edge and a pressure distribution acting over approximately 5 hull frames. At a simulation time of $14.235 \mathrm{~s}$, the jet flows formed by demihull and centre bow entry meet at the top of the arch and the arch slam event commences. The peak arch slam pressure occurs at a simulation time of $14.245 \mathrm{~s}$ over a highly localised region spanning approximately 8 hull frames. The high pressure region shifts forward during the arch slam and at a simulation time of $14.251 \mathrm{~s}$ it is just aft of the jaw line.

The transient variations in slam excitation force were extracted from the simulation by integrating the pressure distributions. Fig. 6 shows the non-overlapping areas over which the pressures were integrated in order to obtain transient records for the demihull, centre bow and arch contributions to the overall slam event, where the coordinate $x$ has its origin at the transom. The arch patch size and elliptical form was selected to capture the region of high pressure shown in Fig. 5 at $14.245 \mathrm{~s}$. The transient force records from the simulation are shown over one wave encounter period in Fig. 7. The slam selected for analysis had a peak slam force of $193 \mathrm{~N}$ which is representative of the mean slam force obtained through simulation. The force records were non-dimensionalised using:

$F^{*}=\frac{F}{\rho g L_{p p}\left(\frac{h_{w}}{2}\right)^{2}}$

where $\rho$ is the density of water, $g$ is the acceleration due to gravity and $h_{w}$ is the wave height.
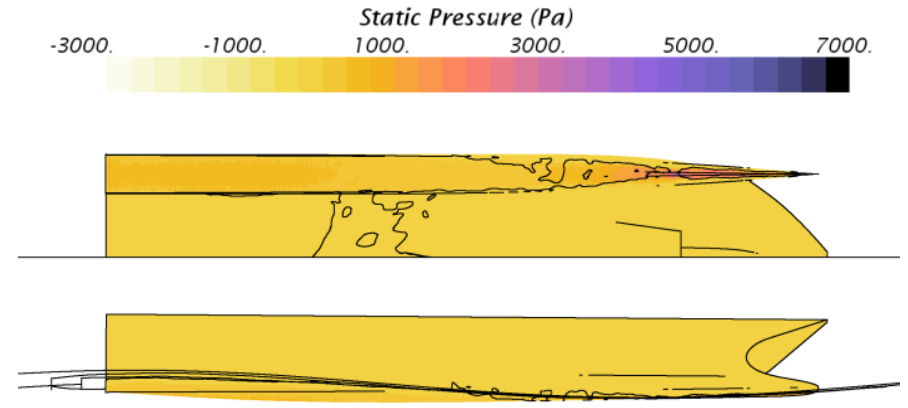

Solution Time: $14.11(\mathrm{~s})$

Maximum Static Pressure: $3223(\mathrm{~Pa})$
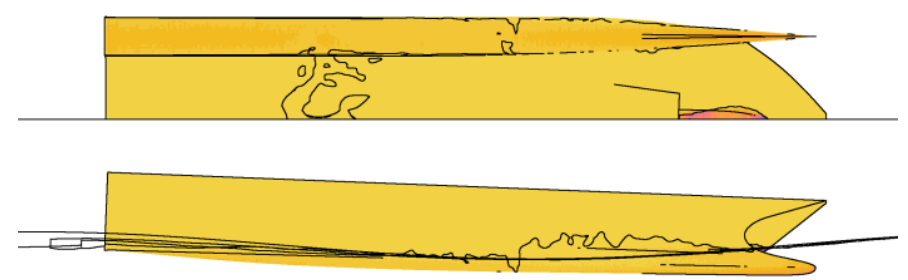

Solution Time: 14.175 (s)

Maximum Static Pressure $13125(\mathrm{~Pa})$

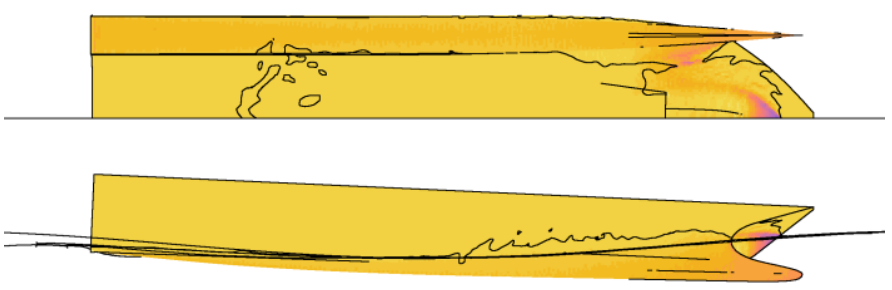

Solution Time: 14.235 (s)

Maximum Static Pressure: $4395(\mathrm{~Pa})$
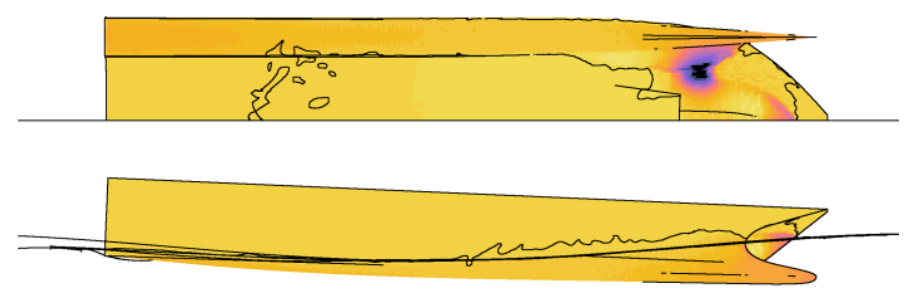

Solution Time: $14.245(\mathrm{~s})$

Maximum Static Pressure:8320(Pa)
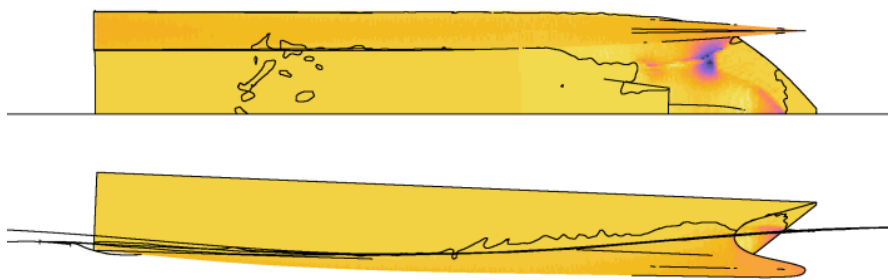

Solution Time: 14.251 (s)

Maximum Static Pressure: $6661(\mathrm{~Pa})$

Fig. 5. Model scale static pressure distributions throughout the overall slam process in regular waves, plan and profile views at each time step. The wetted area boundary, projected free surface boundary and hull feature outlines are also illustrated. 

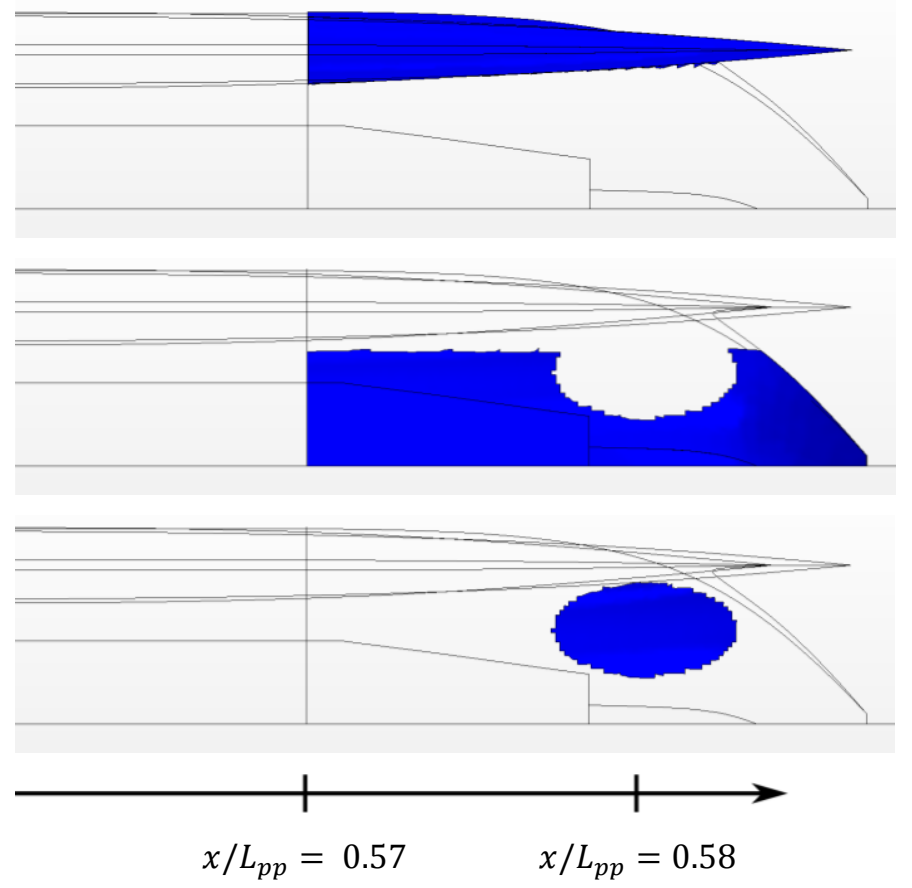

Fig. 6. Force integration patches for the demihull slam (top), centre bow entry (middle) and arch slam (bottom) viewed from below the model.

The demihull bottom slam causes the transient demihull force to rise sharply but results in only a minor deviation from the hydrodynamic force which might be expected without slamming. However, this sharp rise may result in significant increase in the contribution of the demihull force to structural vibration. The centre bow entry has a similar initial rising slope as the demihull entry, but the total transient duration is significantly shorter. The overall slam event ends with the arch slam which has a significantly steeper slope, shorter duration and larger magnitude than displayed in either the demihull or centre bow force records. At the time of arch slam, both the demihull and centre bow forces exhibit a negative spike. In the case of the demihull force, this negative spike is relatively small with the force acting on the demihull remaining positive. The negative spike does cause the centre bow force to become negative, but only with small amplitude, and does not result in particularly large negative gauge pressures (see Fig. 5). In both cases this is probably due to added mass effects resulting from the vertical acceleration generated by the arch slam. After the arch slam the forces acting on the centre bow and arch patches are small and negative with only the hydrodynamic forces acting on the demihull generating lift over this portion of the motion.

The longitudinal position of the centre of pressure on each patch relative to the transom is shown in Fig. 8. This was calculated by dividing the total moment generated by the pressure distribution acting on each patch about the transom by the patch force. Regions where the patch forces are small result in a centre of pressure well forward of the bow, owing to division by the small patch force. For the demihull force, there is relatively little variation between the demihull slam and the arch slam followed by a gradual aft-ward shift. After centre bow entry, the centre bow force acts initially at a similar location to the demihull slam. As the centre bow enters, the leading edge of the centre bow loading moves forward, as does the resultant force centre. At the time of the arch slam, the centre bow force becomes small and negative and, thus, the resultant centre of pressure is well forward of the bow. Once the centre bow force has reached a larger magnitude, the force centre follows that of the demihull closely. Over the majority of the record, the arch patch force is centred between $0.8 \mathrm{~L}$ and $0.83 \mathrm{~L}$, shifting forward after the arch slam. For comparison, the force centre locations estimated through model scale test by Lavroff (2013) and Matsubara (2011) were $x / L_{p p}=0.82$ and 0.83 respectively.

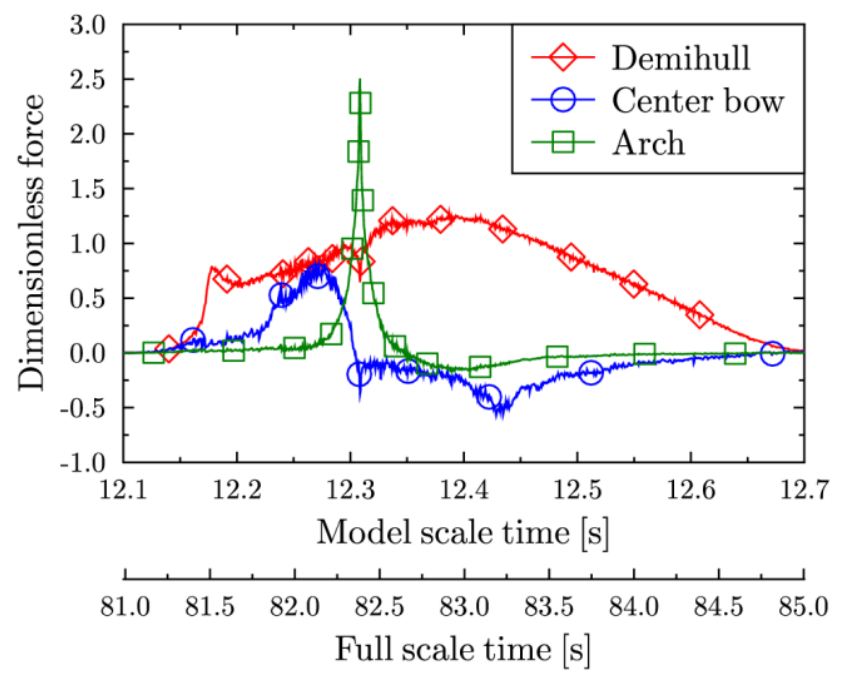

Fig. 7. Transient forces acting on the demihull, centre bow and arch slam.

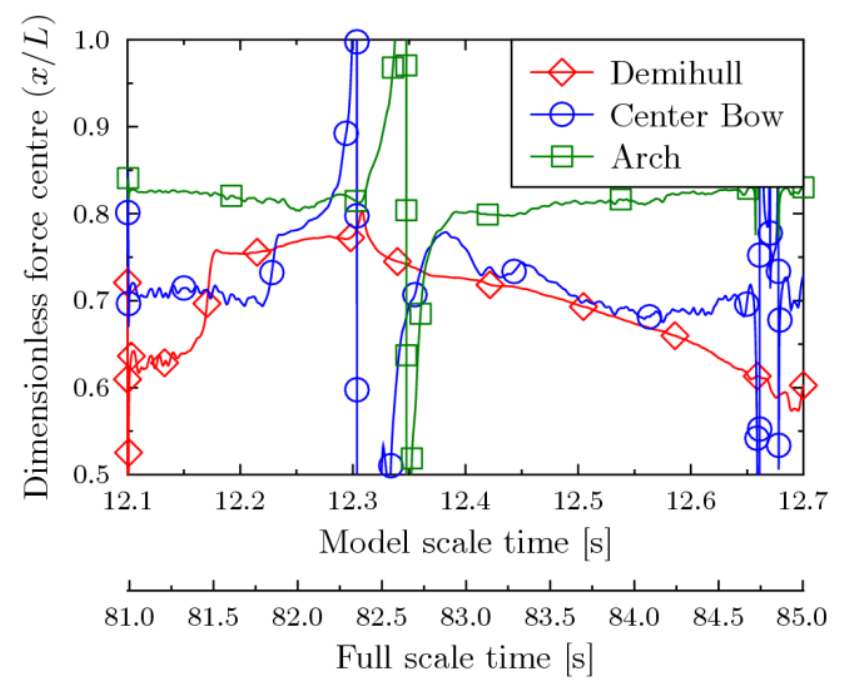

Fig. 8. Longitudinal location of the effective force centre for the pressure distributions acting on the demihull, centre bow and arch patches. 


\section{STRUCTURAL MODEL}

The wet hull girder system was represented using the model presented by McVicar et al. (2015) which was used to investigate the effects of temporal variations in slam excitation. The representative model of the wet ship system, shown in Fig. 9, consists of an Euler beam of stiffness $E I$ and linear density $\rho A$ (which includes added mass) to represent the hull girder. This rests on an elastic foundation representing the hydrostatic forces having a stiffness per unit length $\hat{k}$. An external distributed load $(p)$ acts on the hull girder and is implemented to represent the slam impulse excitation. The governing equation of the system is:

$\rho A \ddot{h}+E I h^{I V}+\hat{k} h=p$

where $h$ is the transverse displacement. The associated boundary conditions representing zero shear force and zero moment at each end of the beam are:

$\left.h^{\mathrm{II}}\right|_{0} ^{L}=0$

$\left.h^{\mathrm{III}}\right|_{0} ^{L}=0$

where a superscript roman numeral has been used to denote derivative differentiation with respect to space and an over-dot for differentiation with respect to time.

Model parameters which are representative of INCAT Tasmania hull 064 (a $112 \mathrm{~m}$ wave piercing catamaran) were presented by McVicar et al. (2015) and are used again here: the selected ship particulars are presented in Table 3 and the beam model parameters are given in Table 4.

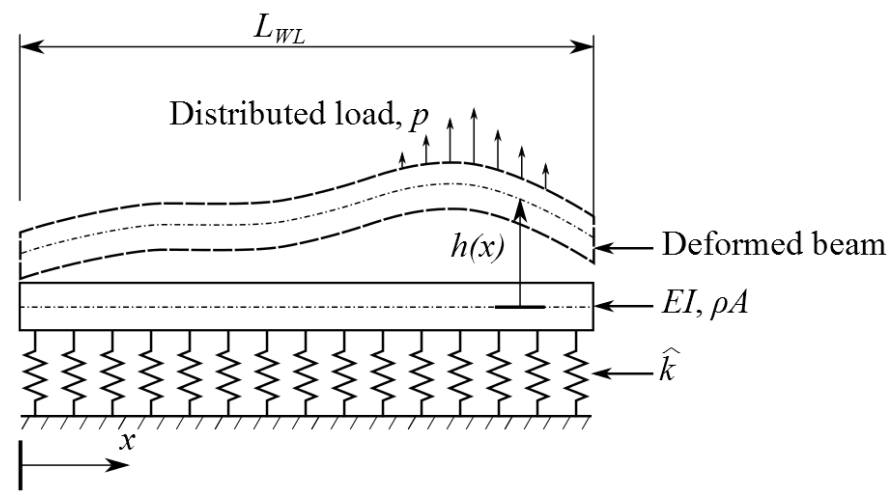

Fig. 9. Schematic of the continuous beam model implemented to analyse the effects of temporal force duration on the modal response (McVicar et al., 2015).
Table 3. Selected ship particulars for a $112 \mathrm{~m}$ INCAT Tasmania wave piercing catamaran (McVicar et al., 2015).

\begin{tabular}{|l|l|l|}
\hline Overall length & 112.5 & $\mathrm{~m}$ \\
\hline Waterline length & 105.6 & $\mathrm{~m}$ \\
\hline Displacement & 2209 & $\mathrm{t}$ \\
\hline Frame spacing & 1.2 & $\mathrm{~m}$ \\
\hline First longitudinal bending frequency & 2.44 & $\mathrm{~Hz}$ \\
\hline Added mass ${ }^{\dagger}$ & 1507 & $\mathrm{t}$ \\
\hline \multicolumn{2}{|l}{ Determined by Amin (2009) for a similar vessel } \\
\hline
\end{tabular}

Table 4. Ship parameters identified for the uniform beam model of a 112 m INCAT Tasmania wave piercing catamaran (McVicar et al., 2015).

\begin{tabular}{|l|l|l|}
\hline Linear density, $\rho A$ & $36 \times 10^{3}$ & $\mathrm{~kg} \mathrm{~m}^{-1}$ \\
\hline Elastic base stiffness, $\hat{k}$ & $69 \times 10^{3}$ & $\mathrm{Nm}^{-2}$ \\
\hline Beam stiffness, $E I$ & $2.10 \times 10^{12}$ & $\mathrm{Nm}^{2}$ \\
\hline $\begin{array}{l}\text { Damping ratio (fundamental } \\
\text { bending mode), } \zeta\end{array}$ & 0.05 & - \\
\hline $\begin{array}{l}\text { Damping ratio (higher order } \\
\text { modes), } \zeta\end{array}$ & 0.1 & - \\
\hline
\end{tabular}

\section{STRUCTURAL RESPONSE}

The full scale structural response to each stage of the slam predicted by the numerical simulation was calculated to understand the effects of the differing spatial and temporal distributions of each slam stage. Froude similarity was used to scale the numerical simulation results. As the wave height is scaled on a hull length basis and the water density and gravitational acceleration are not scaled in equation (2), the relationship between model scale and full scale forces is:

$\frac{F_{f}}{F_{m}}=\left(\frac{L_{f}}{L_{m}}\right)^{3}$

Froude similarity also imposes that the time scales are related by:

$\frac{t_{f}}{t_{m}}=\sqrt{\frac{L_{f}}{L_{m}}}$

where $F$ and $t$ represent a force and the time scale respectively and subscripts $f$ and $m$ represent full and model scales respectively.

For each stage of the slam, the spatial distribution was assumed constant and uniform across a selected span of hull frames. The transient bending moments were extracted at the mid-ship location and at hull frame $74\left(x / L_{p p}=0.84\right)$ for truncated transient modal analyses using one and ten bending modes. 
Fig. 10 shows the bending response to the simulated transient force on the demihull patch distributed over hull frames 55 to 80 . The peak bending moment at frame 74 is significantly larger than that at mid ship. Despite the large temporal and spatial scale of the excitation force, the solution using the fundamental mode alone has significant error in the estimated bending moments at both locations due to truncation of the solution at just one mode. Furthermore, when using one mode the mid ship bending moment is predicted to be negative (hogging) while with ten modes the response is predicted to be positive. As a result of the nodal locations, the fundamental bending mode has a hogging response. At frame 74 a hogging response is predicted due to the demihull patch force as opposed to the sagging moment at mid ship due to the force being localised in this region. The transient bending moments have a similar form to the transient forcing term demonstrating that the structural response to the demihull patch force would be reasonably estimated through quasi-static analysis.

The demihull slam only accounts for a small component of the patch force which is otherwise dominated by the general wave loading which should be considered as a global hull load. However, the effect of the demihull bottom slam can be seen in the mid ship bending moment solution using one mode as a small amplitude decaying oscillation.

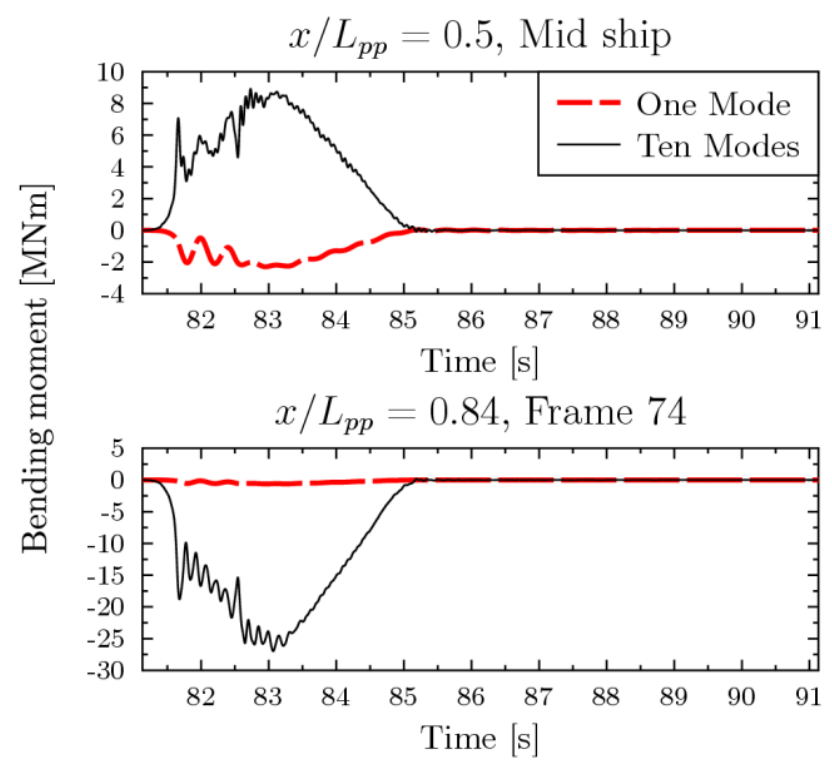

Fig. 10. Full scale response to the demihull transient force extrapolated to full scale and distributed uniformly over frames 55 to 80 .

The bending response to the centre bow patch force applied over frames 80 to 84 is shown in Fig. 11. The peak bending moments are significantly higher than observed for the demihull patch force. The initial response follows the transient force term until the arch slam at $95.5 \mathrm{~s}$ at which time the sharp reduction in transient forcing results in a response characteristic of a step change with oscillation primarily at the fundamental bending frequency. At frame 74 the higher order modes influence the response, increasing the peak bending moment during centre bow entry.

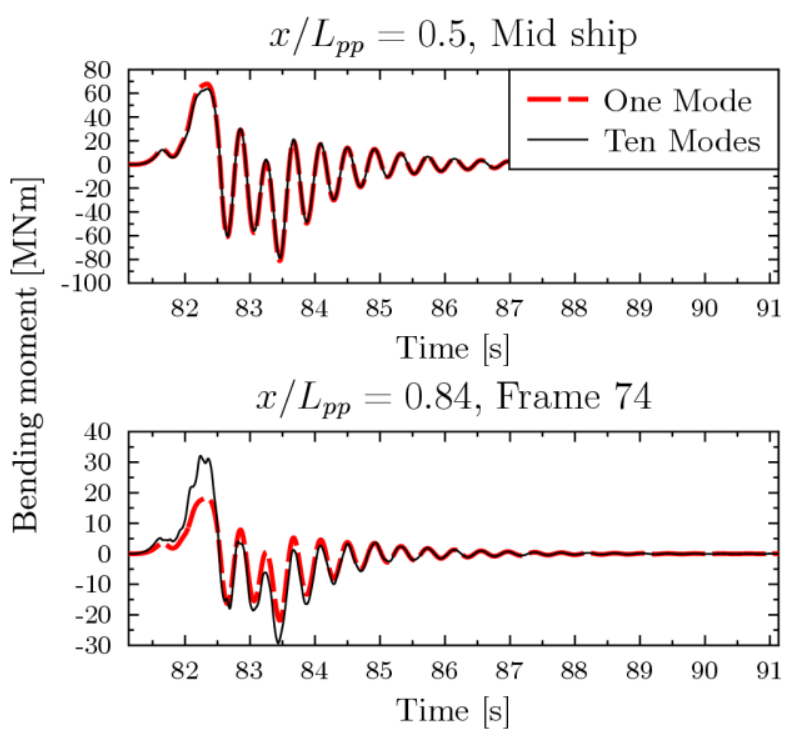

Fig. 11. Full scale response to the centre bow transient force extrapolated to full scale and distributed uniformly over frames 80 to 84 .

Finally, the response to the arch patch transient force is presented in Fig. 12. The transient bending records at both locations resemble impulse responses, owing to the short duration of the excitation. Again, the higher order modes have a significant influence on the early bending response at frame 74 , but the overall response is dominated by the fundamental bending mode.

The peak bending moments using 10 modes for each of the three slam stages are presented in Table 5. For the simulated transient force records, the centre bow entry and arch slam cause similar mid ship bending moments with similar whipping vibration amplitudes. However, the simulated arch slam force magnitude was smaller than the experimental record. Thus, it is expected that the arch slam would impart more energy to the structure than centre bow entry.

When compared to the peak full scale bending moment of $360 \mathrm{MNm}$ extrapolated from model scale, the predicted bending moments in response to each of the patch forces is relatively small. A minor part of this discrepancy can be attributed to the $9 \%$ under-prediction of the arch slam magnitude in simulation. One other major contributor to this error is the location of forward node in the fundamental bending mode which is significantly further aft in the segmented model at $x / L_{p p}=0.67$ (McVicar et al., 2014), than in beam model $x / L_{p p}=0.776$. The proximity of the arch slam and centre bow entry forces to the node influence the magnitude of modal excitation and, in turn, the magnitude of the bending response. 


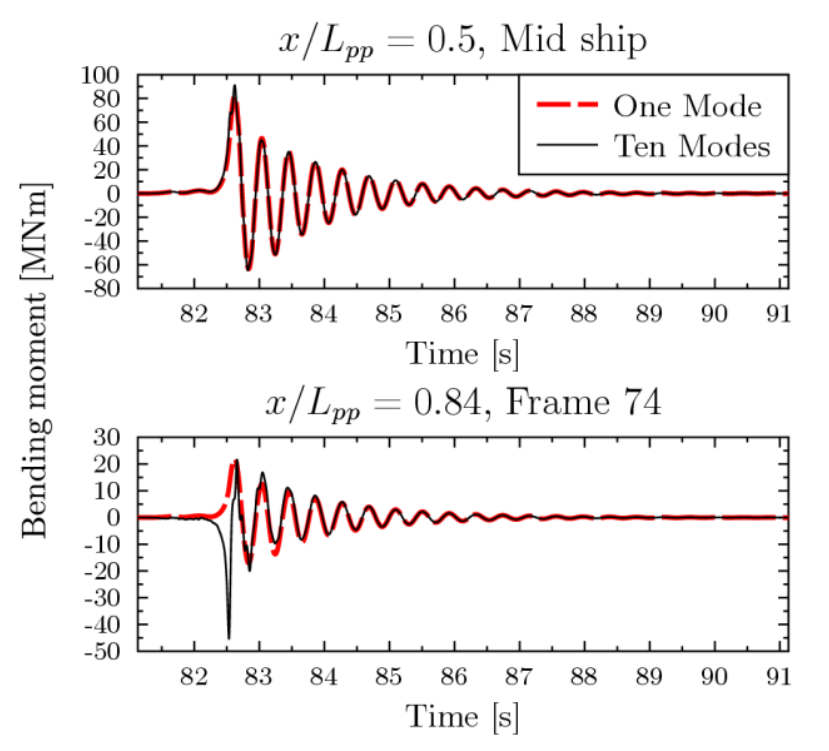

Fig. 12. Full scale response to the arch transient force extrapolated to full scale and distributed uniformly over frames 70 to 80 .

Table 5. Peak bending moments calculated using 10 bending modes.

\begin{tabular}{|l|l|l|l|}
\hline \multirow{2}{*}{ Slam stage } & \multirow{2}{*}{ Location } & \multicolumn{2}{|l|}{$\begin{array}{l}\text { Peak bending } \\
\text { moment }[\mathrm{MNm}]\end{array}$} \\
\cline { 3 - 4 } & & Sag & Hog \\
\hline \multirow{2}{*}{$\begin{array}{l}\text { Demihull } \\
\text { Entry }\end{array}$} & $x / L_{p p}=0.5, \quad$ Mid-ship & 8.9 & -0.1 \\
\cline { 2 - 4 } & $x / L_{p p}=0.84$, Frame 74 & 0.2 & -27.0 \\
\hline $\begin{array}{l}\text { Centre Bow } \\
\text { Entry }\end{array}$ & $x / L_{p p}=0.5, \quad$ Mid-ship & 63.7 & -79.1 \\
\cline { 2 - 4 } & $x / L_{p p}=0.84$, Frame 74 & 32.1 & -29.3 \\
\hline \multirow{2}{*}{ Arch Slam } & $x / L_{p p}=0.5, \quad$ Mid-ship & 91.1 & -64.7 \\
\cline { 2 - 4 } & $x / L_{p p}=0.84$, Frame 74 & 21.6 & -45.4 \\
\hline
\end{tabular}

\section{General Temporal-Spatial Response}

To quantify the effects of variation in the combined temporal and spatial distributions of slam excitation, the structural response was first calculated for rectangular excitation with varying central location, spatial width and temporal duration as shown in Fig. 13. The overall slam impulse identified from model scale experiment (Lavroff, 2009) was used and maintained as constant for all temporal and spatial slam force distributions. Lavroff (2009) identified the force acting on a separate centre bow segment which measured the combined centre bow entry and arch slam forces. Table 6 lists the extrapolated characteristic parameters for the combined centre bow entry and arch slam stages.

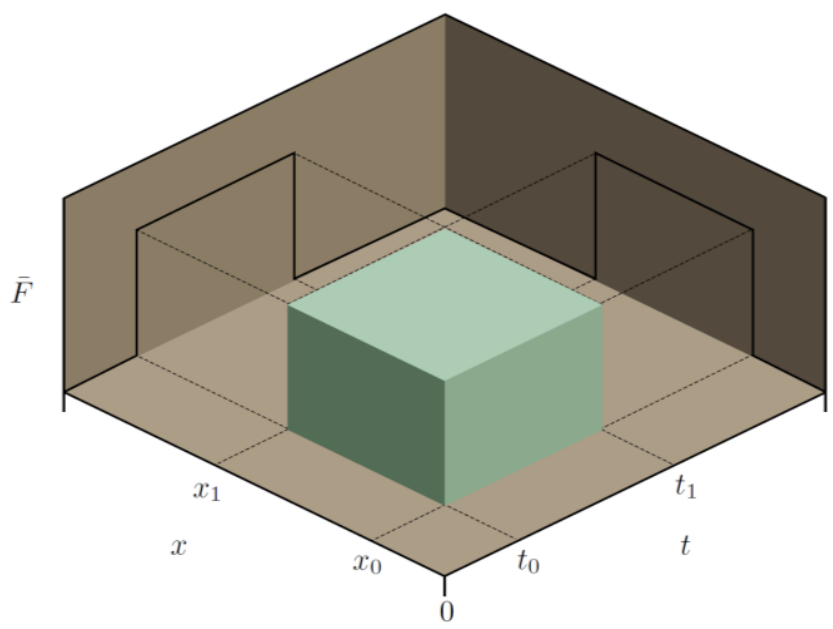

Fig. 13. Simple rectangular force distribution used to investigate the effect of variation in spatial and temporal excitation scales.

Table 6. Characteristic parameters of the overall slam for 38 knots forward speed and $4 \mathrm{~m}$ wave height at a dimensionless encounter frequency of 4.869 (a wavelength to ship length ratio of: $\lambda / L_{p p}=1.34$ ).

\begin{tabular}{|c|c|c|}
\hline Slam impulse ${ }^{\dagger}$ & 5.4 & MNs \\
\hline Peak slam vertical bending moment ${ }^{\dagger *}$ & 360 & $\mathrm{MNm}$ \\
\hline Slam duration $^{\dagger}$ & 0.15 & $\mathrm{~S}$ \\
\hline \multicolumn{3}{|c|}{$\begin{array}{l}\text { Extrapolated from model scale results (Lavroff, 2009). } \\
\text { Bending moment at } x / L_{p p}=0.57\end{array}$} \\
\hline
\end{tabular}

Fig. 14 shows the maximum vertical bending moment in the full scale structural response to a 5.4MNs impulse for variations in the slam location and spatial width for impact durations of $0.001 \mathrm{~s}$ and $0.150 \mathrm{~s}$ (the latter being the lower limit of the overall slam duration extrapolated from model scale) when solving using 10 flexural modes and 1 flexural mode. For the short duration, impulsive, impacts the effects of the higher order modes can be clearly seen for small spatial force widths as peaks in the contours along the horizontal axis, where the six local maxima correspond to anti-nodal locations in the $10^{\text {th }}$ flexural mode. Increases in the spatial force width result in a decrease in the maximum vertical bending moment, but once the force width exceeds $10 \%$ of the vessel length there is little variation in the maximum vertical bending moment with variation in the force location. As demonstrated by McVicar et al. (2015) approximation of the vertical bending moment using just one flexural mode is poor for such short duration, impulsive, forcing. When the impact duration is increased to $0.15 \mathrm{~s}$ (the lower limit of the expected slam duration for the $112 \mathrm{~m}$ INCAT Tasmania catamaran) the approximation using 1 flexural mode is significantly better with the obvious exception in the region of the fundamental bending mode node. 

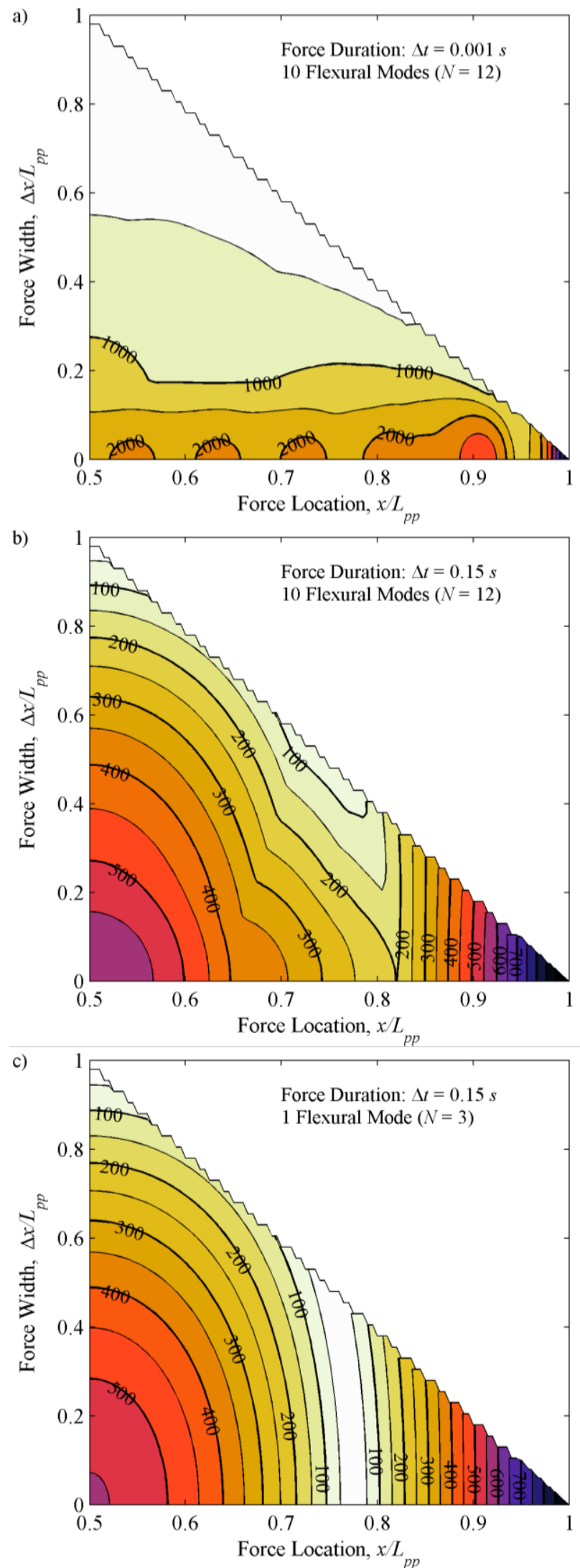

Fig. 14. Full scale maximum vertical bending moment contours (labels in $\mathrm{MNm}$ ) in response to an impulse of $5.4 \mathrm{MNs}$ for variations in force location and width.
Fig. 14 can be further used to understand the significant underestimation of the bending moment using numerical simulation transient forces and the uniform beam model. When the excitation forcing term is of a short duration (such as $1 \mathrm{~ms}$ ) with a finite spatial distribution (such as $\Delta x / L_{p p}=0.1$ ) the peak bending moment in the transient response is relatively insensitive to the impact location (as shown by the near horizontal contours in Fig. 14a). In contrast, for longer duration forcing terms (such as $150 \mathrm{~ms}$ ) the bending moment is highly sensitive to the impact location (as shown by the near vertical contours in Fig. 14c). For the INCAT Tasmania wave piercing catamaran, the transient response near mid ship is so dominated by the fundamental mode, due to the duration of the impact, that contributions from the higher order modes do not alter the mid ship peak bending moment.

\section{CONCLUSIONS}

The slam process which occurs for INCAT Tasmania wave piercing catamarans commences with a bottom slam on the demihulls followed by entry of the centre bow and ends with a wet-deck slam at the top of the arch formed by the centre bow and demihull. Each stage of this slam imparts energy to the structure on differing temporal and spatial scales. A RANSE based numerical simulation was conducted to estimate the transient forcing terms and the effects of the varying scales on the structural response were investigated through a uniform beam model.

The simulated motion and slamming forces were compared to benchmark experimental data. Both the motions and peak slam forces were found to be under-predicted, but the centre bow entry phase was over-predicted. As over-prediction of the centre bow entry force would artificially reduce the simulated relative velocity between the hull and free surface, this is a likely reason that the magnitude of the following arch wet-deck slam is under predicted.

It has been shown that the spatial and temporal distribution of the various sub-events which make up the overall slam event contribute very differently to the structural loads which result from the slam. The demihull bottom slam was found to have minimal contribution to the structural bending response. Based on the simulated transient force terms, the centre bow entry phase and arch wet-deck slam had similar contributions to global bending. However, the wet-deck arch slam magnitude was significantly under-predicted in the simulation and the arch wet-deck slam should therefore have a larger contribution to hull bending loads. Under-prediction of the wet-deck arch slam is a likely result of over-prediction of the centre bow entry force which has a significantly longer duration suggesting that even modest increases in the centre bow entry force can lead to a significant reduction in the peak bending moment.

The effect of variations in spatial and temporal slam scale as well as slam location on the maximum bending moment demonstrated that for INCAT Tasmania wave piercing catamarans the dominance of the fundamental mode results in 
high sensitivity of the peak bending moment to variations in slam location. While the uniform beam model was useful in developing and understanding of the transmission of each slam stage to structural bending, future analysis should include an improved structural model which accounts for longitudinal variation in hull mass and stiffness to provide better representation of the nodal locations, bending modes and hence bending moment response.

\section{ACKNOWLEDGEMENTS}

This work has been supported by INCAT Tasmania Pty Ltd, Revolution Design Pty Ltd, the Australian Research Council, the University of Tasmania and the Australian Maritime College.

\section{REFERENCES}

Amin, Walid. Non-linear Unsteady Wave Loads on Large High-Speed Wave Piercing Catamarans, PhD. Thesis, University of Tasmania. 2009.

Ge, Chunhua., Faltinsen, Odd M., and Moan, Torgeir. "Global Hydroelastic Response of Catamarans Due to Wetdeck Slamming." Journal of Ship Research, 49:1 (2005):24-42.

Hermundstad, O. A., Aarsnes, J. V., Moan, T. "Hydroelastic analysis of a flexible catamaran and comparison with experiments." $3^{\text {rd }}$ International Conference on Fast Sea Transportation. 1995.

Lavroff, Jason. The slamming and whipping vibratory response of a hydroelastic segmented catamaran model, $\mathrm{PhD}$ Thesis, University of Tasmania, 2009.

Lavroff, Jason., Davis, Michael R., Holloway, Damien S., and Thomas, Giles A. "Slamming of High-Speed Catamarans in Severe Sea Conditions Investigated by Hydroelastic Segmented Model Experiments." Proceedings of the $28^{\text {th }}$ Symposium on Naval Hydrodynamics, Office of Naval Research, (2011):169-180.

Lavroff, Jason, Davis, Michael R., Holloway, Damien S. and Thomas, Giles. "Determination of Wave Slamming Loads on High-Speed Catamarans by Hydroelastic Segmented Model Experiments." Transactions of the Royal Institute of Naval Architects, Part A3, International Journal of Maritime Engineering, 153 (2011): A185-A197.

Lavroff, Jason., Davis, Michael R., Holloway, Damien S. and Thomas, Giles A. "Wave Slamming Loads on Wave-Piercer Catamarans Operating at High-Speed Determined by Hydro-Elastic Segmented Model Experiments." Marine Structures, 33 (2013): 120142.
Matsubara, Shinsuke. Ship Motions and Wave-Induced Loads on High Speed Catamarans, PhD Thesis, University of Tasmania, 2011.

McVicar, Jason J., Lavroff, Jason., Davis, Michael R. and Thomas, Giles. "Effect of Slam Force Duration on the Vibratory Response of a Lightweight Highspeed Wave-Piercing Catamaran." Journal of Ship Research, 59:2 (2015): 69-84.

Shahraki, Jalal. The Influence of Hull Form on the Slamming Behaviour of Large High Speed Catamarans, $\mathrm{PhD}$ Thesis, University of Tasmania. 2014.

Thomas, Giles A., Davis, Michael R., Holloway, Damien S. and Roberts, Tim. J. "Transient Dynamic Slam Response of Large High Speed Catamarans." $7^{\text {th }}$ International Conference on Fast Sea Transportation, Ischia, Italy. 2003.

Thomas, G., Davis, M., Holloway, D. and Roberts, T. "The Vibratory Damping of Large High-speed Catamarans." Marine Structures, 2 (2008): 1-22.

Tuitman, J.T., and Malenica. S., "Fully Coupled Seakeeping, Slamming, and Whipping Calculations." Proceedings of the Institution of Mechanical Engineers Part M: Journal of Engineering for the Marine Environment. 223:3 (2009): 439-456.

Varyani, K.S., Gatiganti, R.M., and Gerigk, M. "Motions and Slamming Impact on Catamaran." Ocean Engineering. 27:7 (2000):729-747. 